\title{
X-RAY COMPUTED TOMOGRAPHY-BASED ANALYSIS OF IMPACT DAMAGE PROPAGATION IN COMPOSITE MATERIALS
}

\author{
Yurov V.M. ${ }^{1}$, Goncharenko V.I. ${ }^{2,3}$, Vasiliev S.L. ${ }^{2}$, Dmitriev S.A. ${ }^{2}$, Yurgenson S.A. ${ }^{2}$ \\ 1E.A. Buketov Karaganda State University, Karaganda, Kazakhstan, exciton@list.ru \\ ${ }^{2}$ Moscow Aviation Institute (National Research University), Moscow, Russia, fvo@mai.ru \\ ${ }^{3}$ Institute of Control Sciences. V.A. Trapeznikova, RAS, Moscow, Russia, fvo@mai.ru
}

\begin{abstract}
A composite structure impact damage propagation evaluation procedure using linear detectorequipped X-ray computed tomography scanner has been put forward. An impact damaged carbon-fiber samples research has been carried out to evaluate testing capabilities of internal delamination through $X$-ray computed tomography using linear detector. A special emphasis of the research has been laid on advanced composites. It is linked to the use of the composites for high-load structural elements and necessity of adjusting manufacturing procedures. The procedure helps simplify linear detector tomography analysis of delamination and verify mobile inspection methods data. Besides, the procedure may be used for developing composite structure repair methods. The article includes an example of tomographic image of impact-damaged samples linear attenuation coefficient distribution.
\end{abstract}

Keywords: X-ray tomography, polymer composite materials, aircraft structure, nondestructive methods.

\section{Introduction}

$\mathrm{X}$-ray computed tomography is now the most promising non-destructive method involving borescope inspection of the most critical structural elements dedicated to aerospace industry. Rich tomographic data obtained through the method taking into account spatial position of cross-sections being monitored includes not only bright images but also hundreds of thousands material properties measures with precise spatial reference of each tomographic image element.

Aircraft engineering requires a vast employment of non-destructive methods for every lifecycle stage. It is related to high stresses in structural elements which result in minimal weight of a structure. The highest requirements for finished product non-destructive level are applied to structures created through purpose-oriented manufacturing procedures which influence a material structure. Such procedures include casting, welding, composite product production and so on [1-4].

Among the most precise methods of structure condition evaluation is X-ray computed tomography procedure which helps to a high precision (up to 50 microns) reveal internal discontinuities.

The main parameters of X-ray computed tomography evaluation are based on linear attenuation coefficient analysis, the value of which is dependent on a material density. The coefficient has been applied as the basis for developing a number of parameters to evaluate structure condition [5].

\section{Experimental procedure}

A traditional application of X-ray tomography is searching for internal defects which appear at various stages of a product life cycle. This method is mostly used in manufacturing for casting, welding, composite production and additive technologies. As far as operation is concerned the method is applied for polymeric composites since they feature developing internal damages.

In the context of works performed at MAI (National Research University) Production Planning and Quality Control department the following primary applications of X-ray computed tomography method dedicated to aircraft engineering have been highlighted: 
1) Design stage:

- Developing new behavior models of polymeric composites at static and fatigue loading;

- Evaluating influence of processing factors on polymeric composite structure in regular areas and areas of concern of structures being designed; analysis.

- Studying a process of accumulation and propagation of damages with layer-by-layer

2) Developing manufacturing procedures:

- Adjusting parameter of purpose-oriented manufacturing procedures;

- Defining defect standards acceptable for operation and repair;

- Verifying and detailing (developing methods) capabilities of other non-destructive methods for a certain structure.

3) Structural elements manufacturing stage:

- Selective or overall evaluation of quality of composite products and their elements;

- Verification of non-destructive methods dedicated to composite products in industrial manufacturing.

4) Operational stage:

- Evaluating change of polymeric composite structure in high-load units and elements during operation;

- Verification of non-destructive methods for polymeric composite products being operated.

The emphasis in the context of the research methods development is laid on polymeric composite structures which have a number of dedicated damage propagation testing procedures [6, 7]. It is linked to the use of the composites for high-load structural elements and necessity of adjusting manufacturing procedures.

One of the most dangerous types of polymeric composite operational damages is an impact damage which results in heavy internal delamination. Aircraft structures have requirements as to internal delamination area depending on its detection time through visual or instrumental methods. Each structure may have individual requirements depending on applied testing methods and compulsory inspection periods [8-13].

Ultrasonic and thermal (vacuum) methods are most spread for evaluating internal delamination area. To obtain more detailed data received through these methods it is purposeful to verify them during adjusting inspection methods. The analysis of internal delamination testing capabilities using linear detector X-ray computed tomography involved a research dedicated to 30 and $50 \mathrm{Nm}$ impact-damaged carbon-fiber samples (Figure 1).

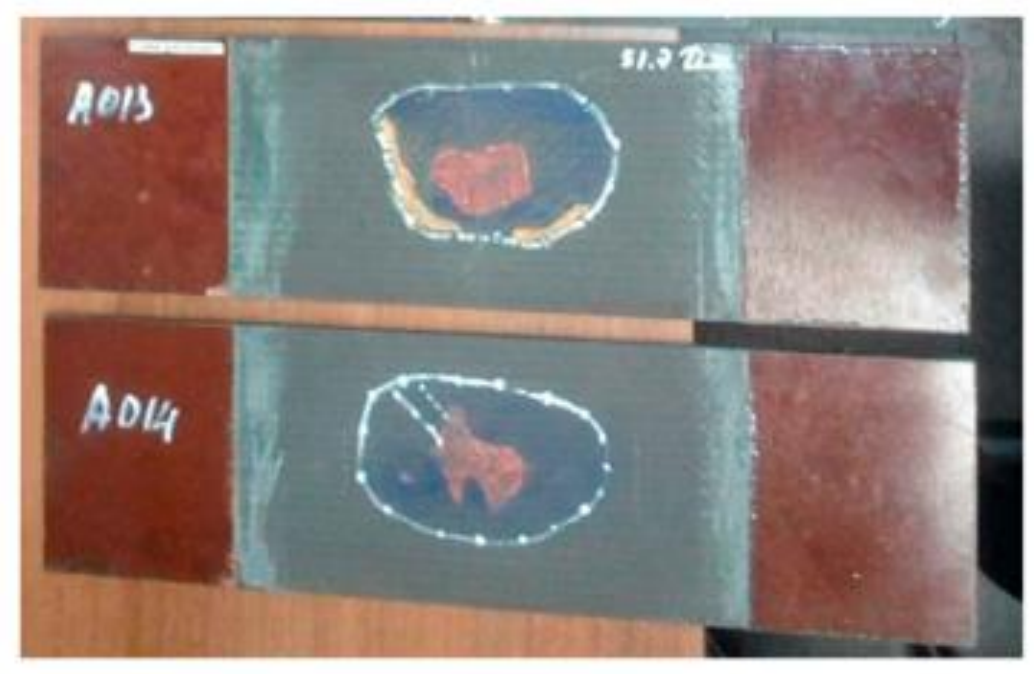

Fig. 1. Samples inspected. General view. 


\section{Results of the experiment and their discussion}

The testing method includes the following stages:

- Layer-by-layer scanning of faulty samples;

- Breakdown of plane sections into areas, which involve an area-averaged analysis of linear attenuation coefficient and its mean square deviation;

- Generation of plane charts of coefficients distribution and analysis of internal defects area.

The necessity of such approach is caused by computed tomography limitations which include inclination of linear attenuation coefficient diagram at two area interface. Thus, it makes composite structure delamination analysis more complicated. You can see an example of impact-damaged samples tomographic image in Figures 2.
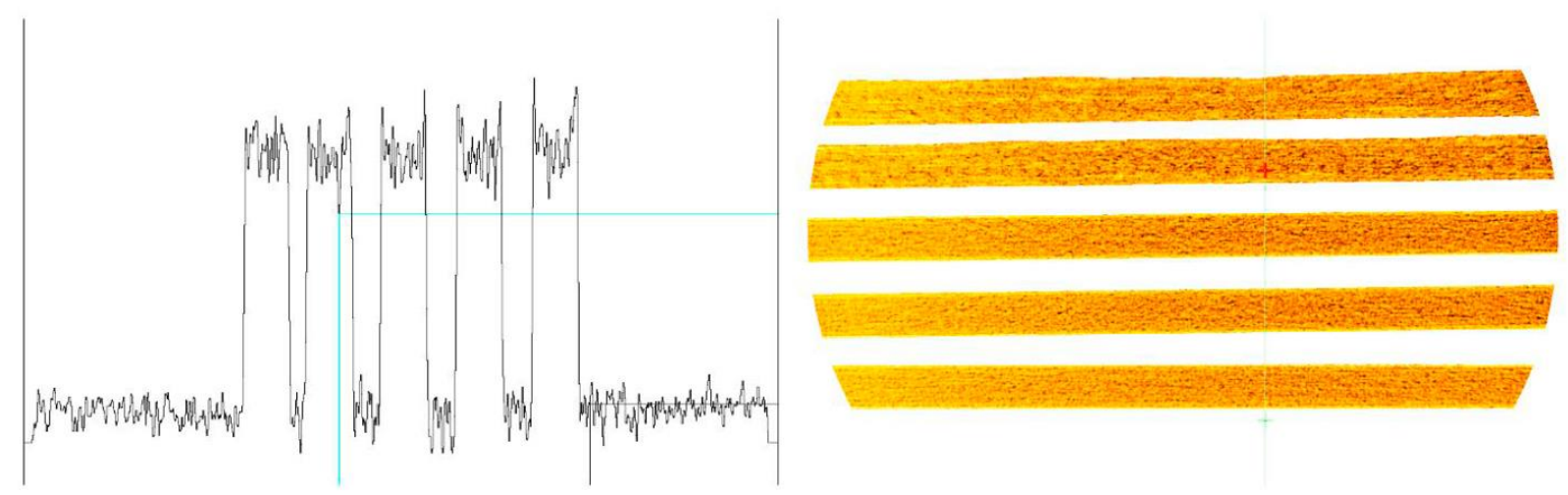

Fig. 2. Tomographic image and linear attenuation coefficient distribution diagram of impact-damaged samples

Plane distribution charts for impact damage points are shown in figures 3 and 4 . The dimension of inspected area is $100 \times 100 \mathrm{~mm}$.

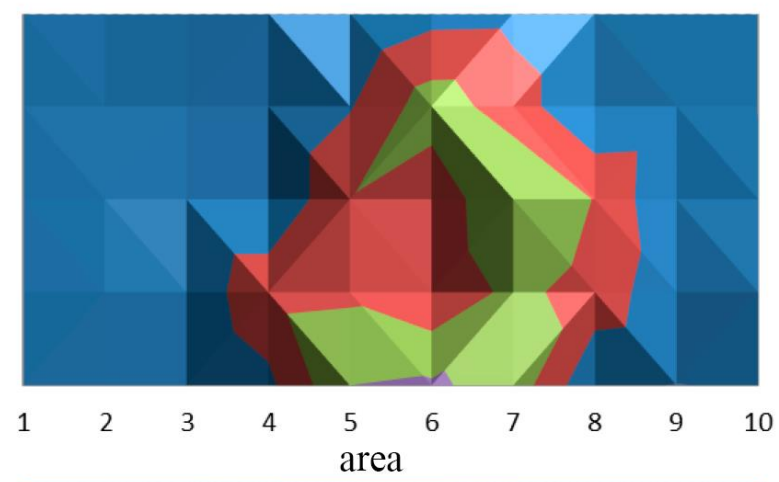

\section{Mean square \\ deviation \\ distribution}

$$
\begin{array}{r}
=4-4,5 \\
=4,5-5 \\
=5-5,5 \\
=5,5-6
\end{array}
$$

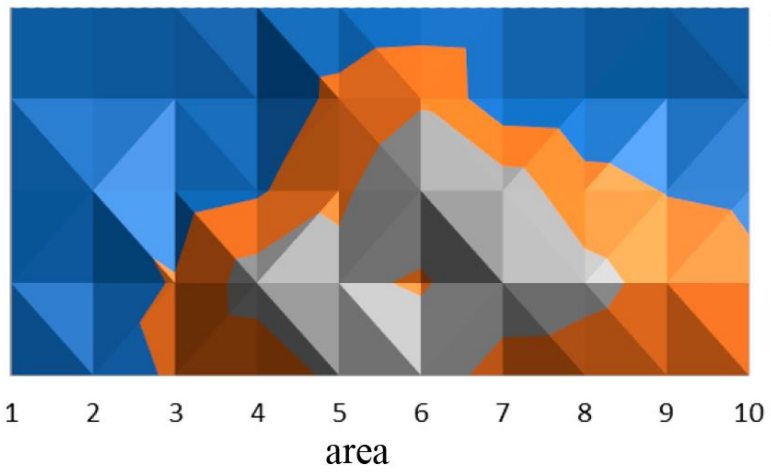

Mean square deviation distribution

$$
\begin{array}{r}
4-4,5 \\
-4,5-5 \\
-5-5,5
\end{array}
$$

Fig. 3. Mean square deviation distribution chart in impact damage area. 

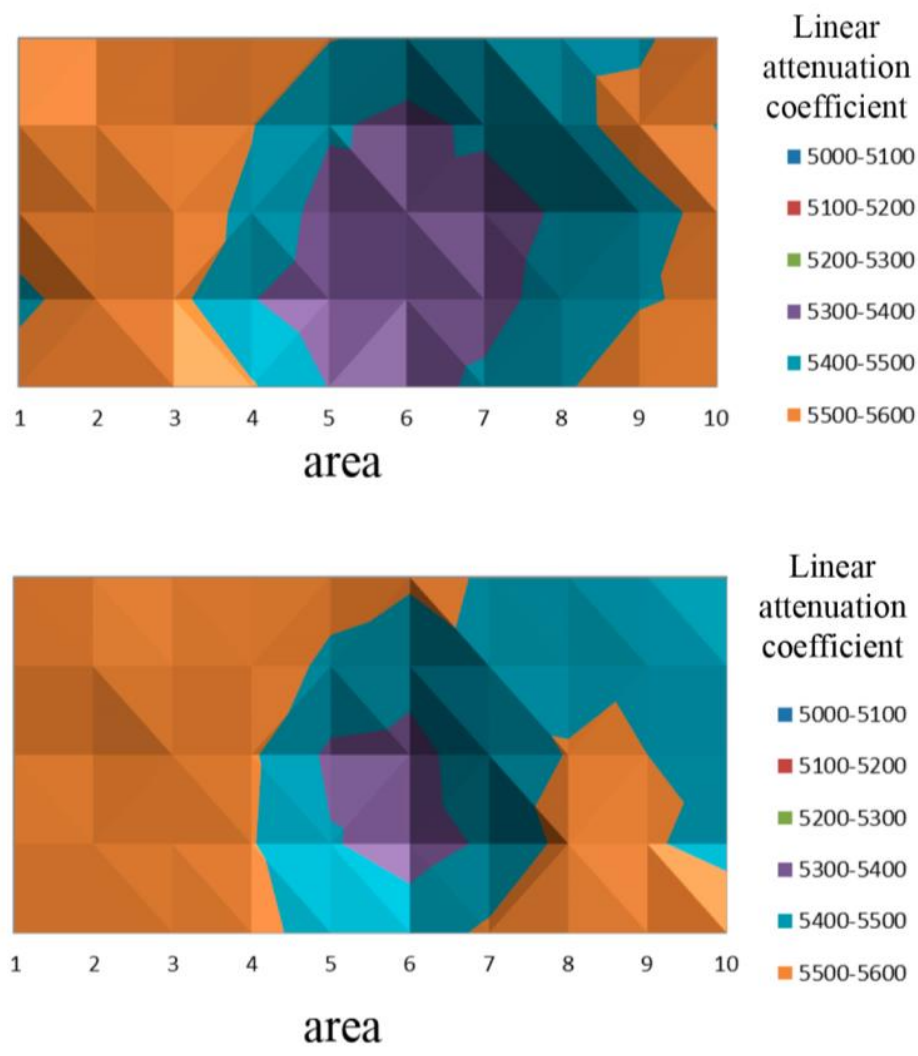

Linear

attenuation

coefficient

- 5000-5100

- $5100-5200$

- 5200-5300

- $5300-5400$

- $5400-5500$

$=5500-5600$

area

Fig. 4. Linear attenuation coefficient distribution in impact damage area.

\section{Conclusion}

As you can see from the charts there is an apparent difference between the impact damage distribution areas for various impact levels. Besides, one can observe that delamination area and distribution may be evaluated through linear attenuation coefficient data, meanwhile mean square deviation chart may be used to evaluate delamination expansion. The averaged characteristics is allowed comparison of different types of materials and thicknesses of structures under the impact of different energies.

The construction of flat maps of the propagation of defects under impact is peculiarity of the proposed method. This map are useful for the finite elements method analysis of CM with averaged mechanical characteristics. It are allowed residual strength of the material and compared results of real tests with FEM results. This method make allowance all defects in structure unlike ultrasonic methods (ultrasonic methods have shading of next to each other defects).

The suggested procedure helps simplify delamination analysis using linear detector tomography scanner and verify mobile inspection methods data. In addition to this the procedure may be applied for developing composite structure repair methods.

\section{REFERENCES}

1 Kluiev V.V., Sosin F.R., Kovalev A.V., Weinberg E.I. et al. Nerazrushaiuschii control I diagnostika, 2-nd edition. Moscow, Mashinostroenie, 2003, 656 p. [in Russian]

2 Weinberg E.I., Weinberg I.A. Computed Tomography Scanners for Non-Destructive Testing and Quantity-related Diagnostics of Aerospace Products. Dvigatel. 2008, No. 2, pp. 19 - 23. [in Russian]

3 Goncharenko V.I., Oleshko V.S. Calculations of Tool Hardness in the Aviation Industry. Russian 
Engineering Research. 2017, Vol.37, No.6, pp. 554-556. DOI: 10.3103/S1068798X17060119.

4 Goncharenko V.I., Oleshko V.S. Determining the surface energy of tools in the aviation industry. Engineering Research. 2017, Vol.37, No.7, pp. 628-630. DOI: 10.3103/S1068798X17070127.

5 Boitsov B.V., Vasiliev S.L., Gromashev A.G., Yurgenson S.A. Metody nerazrushaiuschego kontrolya, primeniaemie dlya konstruktsiy iz perspektivnikh kompozitsionnikh materialov. MAI, Electronic Journal. 27.12.2011. Release No 49. Available at: http://www.mai.ru/science/trudy/. [in Russian]

6 Vasiliev S.L., Artemiev A.V., Yurgenson S.A. Analiz metodom vichislitelnoi rentgenovskoi tomografii vozdeistviaa staticheskoi nagruzki na strukturu polimernogo kompozitsionnogo materiala. Proceedings of $10^{\text {th }}$ International Conference on Non-Equilibrium Processes in Nozzles and Streams (NPNJ 2014), May 25-31, 2014, Alushta. M.: MAI, 2014. pp. 543-545. [in Russian]

7 Vasiliev S.L., Artemiev A.V., Bakulin V.N., Yurgenson S.A. Kontrol obraztov metodom vichislitelnoi rentgenovskoi tomografii pod nagruzkoi. Russian Journal of Nondestructive Testing, 2016, No.5. pp. 63-73.

8 Advisory Circular № 20-107B Composite aircraft structure, USA, FAA, 2009. Available at: www.faa.gov/documentLibrary/media/Advisory_Circular/AC20-107B.pdf.

9 Mikulik Z., Kelly D.W., Prusty B.G., Thomson R.S. Prediction of flange debonding in composite stiffened panels using an analytical crack tip element-based methodology. Composite Structures. 2008, Vol.85, No. 3, pp. 233 - 244. DOI:10.1016/j.compstruct. 2007.10.027.

10 Nishino T., Hirokane D., Nakamae K. X-ray diffraction studies of the environmental deterioration of a transversely loaded carbon-fiber-reinforced composite. Composites Science and Technology. 2001, Vol.61, No.16, pp. 2455 - 2459. DOI:10.1016/S0266-3538(01)00174-9.

11 DeKalbermatten T., Jäggi R., FLüeler P., Kausch H.H., Davies P. Microfocus radiography studies during model interlaminar fracture tests on composites. Journal of Materials Science Letters. 1992, Vol.11, No.9, pp. $543-546$.

12 Yurov V.M., Oleshko V.S. The impact of the environment on the contact potential difference of metal machine parts. Eurasian Physical Technical Journal. 2019, Vol.16, No.1 (31), pp. 99 - 108.

13 Oleshko V.S. Optimal Number of Duralumin Samples in Determining the Surface Energy. Russian Engineering Research, 2019, Vol. 39, No. 3, pp. 272-275. https://doi.org/10.3103/ S1068798X19030183. 